\title{
Defining the Minimally Important Change for the SpondyloArthritis Research Consortium of Canada Spine and Sacroiliac Joint Magnetic Resonance Imaging Indices for Ankylosing Spondylitis
}

\author{
WALTER P. MAKSYMOWYCH, ROBERT G. LAMBERT, L. STEVEN BROWN, and AILEEN L. PANGAN
}

\begin{abstract}
Objective. To define the minimally important change (MIC) in the SpondyloArthritis Research Consortium of Canada (SPARCC) spine and sacroiliac (SI) joint magnetic resonance imaging (MRI) indices in patients with ankylosing spondylitis.

Methods. MRI scans were performed during a placebo-controlled trial of adalimumab (no. NCT00195819). Two independent readers, blinded to treatment and sequence, determined SPARCC scores for the spine and SI joints and a global evaluation of change (GEC; "much worse," "worse," "no change," "better," or "much better"; categories other than "no change" were pooled together as "change") between baseline-Week 12, baseline-Week 52, and Weeks 12-52. Mean absolute changes in SPARCC scores (95\% CI) were calculated for each interval, treatment group, and GEC. Receiver-operating characteristic (ROC) curves were used to identify the MIC. Relationships of MIC to clinical responses were examined.

Results. Reader agreement on GEC evaluations was $>70 \%$. Changes in SPARCC scores were generally comparable between time intervals and treatment groups for "change" and "no change" categories and were combined for each category; change in score was significantly associated with GEC of "change" (area under ROC curves: spine 0.839; SI joints 0.960). ROC curves peaked at values of 5.0 for the spine and 2.5 for SI joints. Placebo-treated patients achieving $>2.5$ unit improvement in SI joint score had significantly better clinical responses than placebo-treated patients who did not achieve such improvement. MRI and clinical responses were uncoupled in adalimumab-treated patients.

Conclusion. We propose that changes of 5.0 for the spine and 2.5 for SI joints define the MIC for the SPARCC MRI indices. (First Release July 1 2012; J Rheumatol 2012;39:1666-74; doi:10.3899/ jrheum.120131)
\end{abstract}

Key Indexing Terms:

ANKYLOSING SPONDYLITIS

MAGNETIC RESONANCE IMAGING

SPONDYLOARTHRITIS RESEARCH CONSORTIUM OF CANADA

ADALIMUMAB

MINIMALLY IMPORTANT CHANGE

Tumor necrosis factor- $\alpha$ (TNF- $\alpha$ ) inhibition has changed treatment practices for ankylosing spondylitis (AS), a disease for which only nonsteroidal antiinflammatory drugs (NSAID) were previously proven to be effective. Clinical trials with

From the Departments of Medicine and Radiology, University of Alberta, Edmonton, Alberta, Canada, and Abbott, Abbott Park, Illinois, USA.

Funded by Abbott. Dr. Maksymowych has received research grants and/or consulting fees or other remuneration from Abbott, Merck, and Pfizer. Dr. Lambert has received consulting fees from Abbott and Perceptive Informatics. Dr. Pangan and Mr. Brown are current and former employees of Abbott, respectively, and may hold Abbott stock or stock options. Dr. Maksymowych is a Scientist of the Alberta Heritage Foundation for Medical Research.

W.P. Maksymowych, MBChB, FRCP(C), Professor of Medicine, Department of Medicine, University of Alberta; R.G. Lambert, MBChB, FRCP $(C)$, Professor, Department of Radiology, University of Alberta; L.S. Brown, MS, Abbott; A.L. Pangan, MD, Immunology Development, Abbott Address correspondence to Dr. W.P. Maksymowych, Alberta Heritage Foundation for Medical Research, Edmonton, Alberta T6G 2S2, Canada. E-mail: walter.maksymowych@ualberta.ca

Full Release Article. For details see Reprints/Permissions at jrheum.org Accepted for publication May 10, 2012.
TNF- $\alpha$ agents have provided insights into the unique challenges of assessing efficacy of new therapies for AS. The current limitations in measuring disease activity and treatment response in AS are 2-fold. First, validated clinical outcome measures in AS are largely subjective and primarily assess symptoms ${ }^{1,2}$. Second, conventional radiography and the modified Stoke Ankylosing Spondylitis Spine Score used to quantify structural damage in AS reflect chronic changes of bone erosion and bone formation ${ }^{3}$, rather than the underlying inflammatory processes that lead to bone damage.

The use of magnetic resonance imaging (MRI) addresses the need for a more objective measure of disease activity and treatment response in AS. MRI techniques have afforded physicians the opportunity to monitor changes in inflammation, rather than the resulting bone damage typically seen on radiographs. Through the incorporation of fat-suppression techniques [e.g., short-tau inversion recovery (STIR) sequences], MRI enables direct visualization of inflammatory lesions within the bone marrow that are often obscured by 
marrow fat ${ }^{4}$. These lesions are thought to be predictive of future locations of erosion and subsequent osteoproliferation, and thus may offer detection and objective monitoring of active disease, advantages not otherwise possible with plain radiography in patients with $\mathrm{AS}^{5,6,7}$.

The SpondyloArthritis Research Consortium of Canada (SPARCC) MRI indices are validated scoring methodologies for spine and sacroiliac (SI) joint inflammation in patients with $A S^{8,9,10}$. The SPARCC MRI indices assess the presence, 3-dimensional extent, and signal intensity of active inflammatory lesions represented by bone marrow edema (BME), in the spine and SI joints of affected patients. In the spine, the scoring system measures BME in the bone marrow of discovertebral units (DVU), each unit representing the region between 2 imaginary lines drawn through the middle of adjacent vertebrae. The 6 worst DVU are selected for assessment, a method that has been shown to be equally discriminatory as an assessment of all 23 DVU $^{11}$. The scoring system also measures BME in the iliac and sacral bone marrow of the SI joints by assessing lesions in consecutive coronal slices through the synovial portion of the joint.

In a randomized controlled trial of patients with longstanding AS, evaluation of changes in the SPARCC MRI scores of the spine and SI joints demonstrated a significant reduction in inflammation following treatment with the TNF- $\alpha$ inhibitor adalimumab versus placebo at Week $12^{12}$. These results indicate that changes in BME can be detected using the SPARCC MRI indices as early as 12 weeks after initiation of effective therapy.

While the SPARCC MRI indices have proved to be useful discriminatory tools for the assessment of inflammation in groups of patients with AS, a threshold defining what constitutes a minimally important change (MIC) in the individual patient has not been described. An MIC is needed to determine the number of patients actually showing an important change in a particular instrument or outcome measure in response to a therapeutic agent. The MIC can be the basis for determining the minimal clinically important difference $(\mathrm{MCID})^{13}$. As an example, a change in the total Sharp score of 5 units or more over 1 year is a widely used MCID to indicate the occurrence of radiographic progression in individual patients with rheumatoid arthritis (RA), as this constitutes the amount of change judged by expert readers to be clinically relevant progression when reading sets of radiographs obtained at 1 -year time intervals ${ }^{14}$. We sought to determine the MIC for inflammatory lesions in the spine and SI joints scored by expert radiologists using the SPARCC MRI indices.

\section{MATERIALS AND METHODS}

Patients. Adult patients $\geq 18$ years of age who met the definition of AS based on the modified New York criteria ${ }^{15}$ were eligible for enrollment in this Canadian study of patients with AS. Patients must have had active AS at study entry, defined as fulfillment of at least 2 of the following 3 conditions: a Bath Ankylosing Spondylitis Disease Activity Index (BASDAI) score $\geq 4 \mathrm{~cm}$, a visual analog scale (VAS) score for total back pain $\geq 40 \mathrm{~mm}$ (scale $0-100$ $\mathrm{mm}$ ), and/or morning stiffness $\geq 1$ hour. Patients must have had an inadequate response to or intolerance of 1 or more NSAID. Additionally, patients were allowed to have failed at least 1 disease-modifying antirheumatic drug (DMARD), although this was not a requirement for study entry. Patients were allowed to continue concomitant therapy with sulfasalazine (SSZ; 3 g/day) and/or methotrexate (MTX; $\leq 25 \mathrm{mg} /$ week) and/or hydroxychloroquine ( $\leq$ $400 \mathrm{mg} /$ day) and/or prednisone ( $\leq 10 \mathrm{mg} /$ day) and/or NSAID as long as the doses of these drugs remained stable for 4 weeks prior to the baseline visit.

Patients were ineligible for the study if they had received prior treatment with a TNF- $\alpha$ inhibitor, had radiological evidence of total spinal ankylosis, or had received cyclosporine, azathioprine, or DMARD (other than MTX and/or SSZ and/or hydroxychloroquine) within 4 weeks prior to baseline.

Our study was approved by an independent ethics committee at each study site. All patients provided written informed consent, and the study was performed in accord with the ethics principles of the Declaration of Helsinki.

Study design. The M03-606 study was a multicenter, randomized, doubleblind, placebo-controlled trial of adalimumab for the treatment of patients with active AS in Canada (clinicaltrials.gov identifier NCT00195819) ${ }^{12}$. Patients were randomized in a 1:1 ratio to receive blinded adalimumab $40 \mathrm{mg}$ or placebo every other week during the initial 24-week double-blind period. Patients completing 24 weeks of treatment were eligible to enter into an extension study and receive open-label adalimumab $40 \mathrm{mg}$ every other week for a period of up to 5 years. Patients failing to meet the Assessment of SpondyloArthritis International Society criteria for $20 \%$ improvement in disease activity (ASAS20) at Weeks 12, 16, or 20 were eligible to receive openlabel adalimumab $40 \mathrm{mg}$ every other week for the remainder of the doubleblind period (early escape option).

Imaging. MRI of the spine and SI joints was performed at baseline, Week 12 , and Week 52 as described ${ }^{8,9,12}$. STIR sequences were obtained for both the spine and SI joints using the following measures: time to recovery 2720-3170 $\mathrm{ms}$; time to inversion $140 \mathrm{~ms}$; time to echo $38-61 \mathrm{~ms}$. STIR sequences of the spine were obtained in a sagittal orientation, 12-15 slices of 4-mm thickness, divided into 2 parts: the entire cervical spine and most of the thoracic spine, and the lower portion of the thoracic spine and entire lumbar spine. STIR sequences of SI joints were obtained in a coronal plane tilted parallel to the long axis of the SI joint, and 12 slices of 4-mm thickness were acquired. T1-weighted spin-echo images of the entire spine and the SI joints were also obtained for use as anatomical references.

MRI scoring. Two independent readers, blinded to randomized treatment assignment and time sequence (i.e., study week), scored the MRI using the SPARCC MRI indices for spine (range 0-108) and SI joints (range 0-72). Details of the SPARCC scoring methodologies have been described ${ }^{8,9,10}$. Additionally, an overview of the SPARCC scoring methodologies can be found at www.arthritisdoctor.ca. Readers also compared MRI between blinded timepoints and rated each comparison according to a 5-category global evaluation of change (GEC) as "much worse," "worse," "no change," "better," or "much better." After unblinding, this allowed for evaluation of comparisons between baseline and Week 12, baseline and Week 52, and Week 12 and Week 52. Interreader agreement was assessed by determining the proportion of concordant reads for the GEC to total available reads. Only the cases in which both readers agreed on the original 5-category GEC were considered for this analysis of the MIC. Reader agreement across the distribution of spine and SI joint SPARCC MRI scores and change from baseline to Week 12 and baseline to Week 52 were assessed by Bland-Altman plots ${ }^{16,17}$. These plots illustrate the interreader difference across the range of SPARCC MRI scores.

Clinical response. Clinical response measures included the ASAS20. This measure is defined as improvement $\geq 20 \%$ and absolute improvement $\geq 10$ units in 3 of 4 domains, with no deterioration (defined as a worsening $\geq 20 \%$ and a net worsening $\geq 10$ units) in the remaining domain. The 4 domains are patient's global assessment of disease activity VAS, total back pain VAS, functionality [Bath Ankylosing Spondylitis Functional Index (BASFI)] and inflammation (mean of questions 5 and 6 on the BASDAI scale) ${ }^{1}$, ASAS40 (improvement $\geq 40 \%$ and absolute improvement $\geq 20$ units from baseline in $\geq 3$ of the 4 domains of the ASAS20 with no worsening in the potential Personal non-commercial use only. The Journal of Rheumatology Copyright @ 2012. All rights reserved. 
remaining domain), a 50\% improvement in the BASDAI (BASDAI50), clinically important improvement (CII) in the Ankylosing Spondylitis Disease Activity Score (ASDAS ${ }^{18}$; improvement $\geq 1.1$ ), and major improvement (MI) in ASDAS (improvement $\geq 2.0$ ).

Statistical analyses. For this analysis, categories other than "no change" in the GEC were pooled together as "change." Change in the numerical SPARCC score was expressed as an absolute change, independent of the direction of change (i.e., values are reflective of both "progression" and "improvement"). Mean absolute changes in SPARCC scores and 95\% CI were summarized by intervisit comparison (baseline to Week 12, baseline to Week 52, and Week 12 to Week 52), treatment group (adalimumab or placebo), and GEC category (pooled "change" or "no change"). Receiver-operating characteristic (ROC) curves were generated on the basis of a logistic regression model of "change"/"no change" from the GEC compared with change in the SPARCC MRI scores. ROC curves were used to predict the efficiency with which the SPARCC MRI indices discriminated GEC of "change" from "no change" by plotting the sensitivity against 1 - the specificity for all values of absolute change in the SPARCC score. A plot of the sensitivity and specificity against absolute change in the SPARCC score was used to identify the point at which the 2 curves met; this convergence point was defined as an acceptable threshold for defining "change."

The percentages of patients who improved beyond the identified MIC for SPARCC scores of the spine and SI joints were summarized. The clinical response rates of patients improving or failing to improve beyond the MIC for MRI assessments of the spine and SI joints were compared between and within treatment groups using chi-square analysis.

\section{RESULTS}

Defining the MIC for SPARCC scores of the spine and SI joints. Patient demographics and disease characteristics at baseline for the 38 and 44 patients randomized to adalimum$\mathrm{ab}$ and placebo, respectively, were indicative of a population with active $\mathrm{AS}^{12}$. As reported, there were no significant differences in the baseline disease characteristics between treatment groups. About $95 \%$ and $65 \%$ of patients had baseline SPARCC scores $>0$ for the spine and SI joints [adalimumab: spine 97\%, mean (SD) $=16.0(15.6)$ and SI joints 63\%, mean $=5.7$ (9.0); placebo: spine 93\%, mean = 19.9 (19.8) and SI joints $66 \%$, mean $=7.5(10.0)]^{12}$. Following 52 weeks of treatment, all 38 patients initially randomized to adalimumab and 42 of 44 initially randomized to placebo had evaluable MRI.

Interreader agreement on the 5-category GEC ("much worse," "worse," "no change," "better," or "much better") was noted to be higher for MRI assessments of the SI joints than of the spine at each visit interval (Table 1). For the majority of the GEC evaluations in which readers agreed on "change" or "no change," the $95 \%$ CI of the absolute changes in numerical SPARCC scores of both the spine and SI joints showed comparability between treatment groups and among visit comparisons (Tables 2 and 3). Therefore, all cases were combined across treatment groups and visit comparisons in the analysis of the MIC.

Based on 100 spine and 154 SI joint assessments in which both readers concluded "no change" in the GEC, the mean absolute changes in SPARCC scores were 4.2 (95\% CI 2.6-5.8) and 1.1 (95\% CI 0.6-1.6) for spine and SI joints, respectively. Conversely, based on 72 spine and 40 SI joint assessments in which the readers concluded "change," the mean absolute changes in SPARCC scores were 15.9 (95\% CI 12.6-19.3) and 10.8 (95\% CI 8.6-13.0), respectively. A review of the Bland-Altman plots showed that interreader differences were similar across the range of change scores (data not shown).

Absolute changes in SPARCC scores of the spine and SI joints were significantly associated with "change" as determined by the GEC (areas under the ROC curve for spine and SI joints were 0.839 and 0.960 , respectively; Figures $1 \mathrm{~A}$ and 1B). Absolute changes between 4 and 5 in the SPARCC scores for the spine were associated with sufficiently high levels of both sensitivity and specificity (about $80 \%$ for both) for a GEC of "change" (Figure 1A). Absolute changes between 2.0 and 2.5 in the SPARCC scores for SI joints were associated with even higher levels of sensitivity and specificity (about $90 \%$ for both; Figure 1B).

To further quantify the absolute change in SPARCC scores that would be an acceptable threshold to separate "change" from "no change," the modeled sensitivities and specificities for the spine and SI joint assessments were plotted against absolute changes in SPARCC scores (Figures 2A and 2B). The lines converged at absolute changes of 5.0 and 2.5 for the spine and SI joints, respectively, suggesting that changes of 5.0 SPARCC units in the spine and 2.5 SPARCC units in the SI joints define the minimally important changes in inflammation on MRI for patients with AS.

MIC and clinical response. Higher percentages of patients randomized to adalimumab (57.9\%) demonstrated improvements in SPARCC scores of the spine that surpassed the identified MIC threshold (5.0 SPARCC units) within 12 weeks of treatment when compared with patients randomized to placebo $(27.3 \% ; \mathrm{p}=0.005$ for difference between treatment groups). In contrast, there were no differences between the percentages of patients who improved beyond the MIC for SPARCC scores of the SI joints (2.5 SPARCC units) follow-

Table 1. Interreader agreement on the 5-category global evaluation of change.

\begin{tabular}{lccc}
\hline & Baseline to & Baseline to & Week 12 to \\
& Week 12 & Week 52 & Week 52 \\
\hline Spine & $\mathrm{n}=82$ & $\mathrm{n}=80$ & $\mathrm{n}=80$ \\
$\quad$ Agreement between readers, $\mathrm{n}(\%)$ & $61(74.4)$ & $58(72.5)$ & $53(66.3)$ \\
SI joints & $\mathrm{n}=82$ & $\mathrm{n}=79$ & $\mathrm{n}=79$ \\
Agreement between readers, $\mathrm{n}(\%)$ & $68(82.9)$ & $61(77.2)$ & $65(82.3)$ \\
\hline
\end{tabular}

SI: sacroiliac. 
Table 2. Summary statistics of absolute change in SPARCC score for spine by global evaluation of change.

\begin{tabular}{lcccccc}
\hline $\begin{array}{l}\text { Comparison } \\
\text { Global Evaluation } \\
\text { of Change }\end{array}$ & Treatment & $\mathrm{N}$ & Mean & 95\% Lower CI & 95\% Upper CI \\
\hline Baseline to Week 12 & No change & Adalimumab & 17 & 3.0 & 0.35 & 5.65 \\
& & Placebo & 17 & 2.4 & 1.06 & 3.65 \\
& Change & Adalimumab & 13 & 16.5 & 12.19 & 20.88 \\
& & Placebo & 14 & 8.4 & 4.72 & 12.14 \\
Baseline to Week 52 No change & Adalimumab & 20 & 5.0 & 1.72 & 8.28 \\
& & Placebo & 16 & 6.9 & 1.53 & 12.34 \\
& Change & Adalimumab & 6 & 17.2 & 6.16 & 28.18 \\
& & Placebo & 16 & 23.9 & 13.44 & 34.37 \\
Week 12 to Week 52 No change & Adalimumab & 16 & 0.7 & 0.32 & 0.99 \\
& & Placebo & 14 & 7.6 & -0.97 & 16.19 \\
& Change & Adalimumab & 10 & 3.0 & 0.63 & 5.37 \\
& & Placbo & 13 & 22.9 & 13.68 & 32.09 \\
All visits & No change & Adalimumab & 53 & 3.0 & 1.55 & 4.54 \\
& & Placebo & 47 & 5.5 & 2.49 & 8.47 \\
& Change & Adalimumab & 29 & 12.0 & 8.40 & 15.60 \\
& & Placebo & 43 & 18.6 & 13.52 & 23.59 \\
\hline
\end{tabular}

SPARCC: SpondyloArthritis Research Consortium of Canada.

Table 3. Summary statistics of absolute change in SPARCC score for SI joints by global evaluation of change.

\begin{tabular}{|c|c|c|c|c|c|c|}
\hline Comparison & $\begin{array}{c}\text { Global Evaluation } \\
\text { of Change }\end{array}$ & Treatment & $\mathrm{N}$ & Mean & $95 \%$ Lower CI & 95\% Upper CI \\
\hline \multirow[t]{4}{*}{ Baseline to Week 12} & \multirow[t]{2}{*}{2 No change } & Adalimumab & 28 & 1.3 & -0.24 & 2.77 \\
\hline & & Placebo & 25 & 0.5 & 0.16 & 0.88 \\
\hline & \multirow[t]{2}{*}{ Change } & Adalimumab & 6 & 14.5 & 8.06 & 20.94 \\
\hline & & Placebo & 9 & 7.3 & 3.64 & 11.03 \\
\hline \multirow[t]{4}{*}{ Baseline to Week 52} & \multirow[t]{2}{*}{ No change } & Adalimumab & 26 & 1.2 & -0.37 & 2.75 \\
\hline & & Placebo & 24 & 1.4 & -0.09 & 2.88 \\
\hline & \multirow[t]{2}{*}{ Change } & Adalimumab & 3 & 14.5 & 0.50 & 28.50 \\
\hline & & Placebo & 8 & 13.9 & 8.02 & 19.85 \\
\hline \multirow[t]{4}{*}{ Week 12 to Week 52} & \multirow[t]{2}{*}{ No change } & Adalimumab & 27 & 0.2 & 0.07 & 0.41 \\
\hline & & Placebo & 24 & 1.9 & 0.18 & 3.57 \\
\hline & \multirow[t]{2}{*}{ Change } & Adalimumab & 4 & 2.9 & 0.02 & 5.73 \\
\hline & & Placebo & 10 & 11.3 & 6.28 & 16.22 \\
\hline \multirow[t]{4}{*}{ All visits } & \multirow[t]{2}{*}{ No change } & Adalimumab & 81 & 0.9 & 0.20 & 1.60 \\
\hline & & Placebo & 73 & 1.3 & 0.53 & 1.98 \\
\hline & \multirow[t]{2}{*}{ Change } & Adalimumab & 13 & 10.9 & 6.52 & 15.32 \\
\hline & & Placebo & 27 & 10.7 & 8.10 & 13.38 \\
\hline
\end{tabular}

SPARCC: SpondyloArthritis Research Consortium of Canada.

ing 12 weeks of treatment (28.9\% vs $31.8 \%$ for patients randomized to adalimumab and placebo, respectively; $\mathrm{p}=0.78$ ). In general, 12 weeks of treatment with adalimumab was associated with better clinical responses than treatment with placebo regardless of whether SPARCC scores improved beyond the MIC (Table 4). On the other hand, placebo-treated patients who demonstrated improvements in SI joint SPARCC scores beyond the MIC within the first 12 weeks of treatment achieved significantly better clinical responses than placebo-treated patients who did not demonstrate such improvements. There was also a trend for better ASDAS CII and ASDAS MI responses among adalimumab-treated patients who had improvements in SPARCC scores beyond the MIC, although the differences were not statistically significant.

\section{DISCUSSION}

MRI scoring systems for spinal and SI joint inflammation in AS have been shown to be highly discriminatory between treatment groups in placebo-controlled trials of TNF- $\alpha$ inhibitors $12,19,20,21,22,23$. Although limited histopathological data from biopsies of the spine and SI joints show that changes in MRI inflammation correlate well with changes in histopathological scores for inflammation ${ }^{24}$, the correlation with clinical measures such as BASDAI, BASFI, and back 

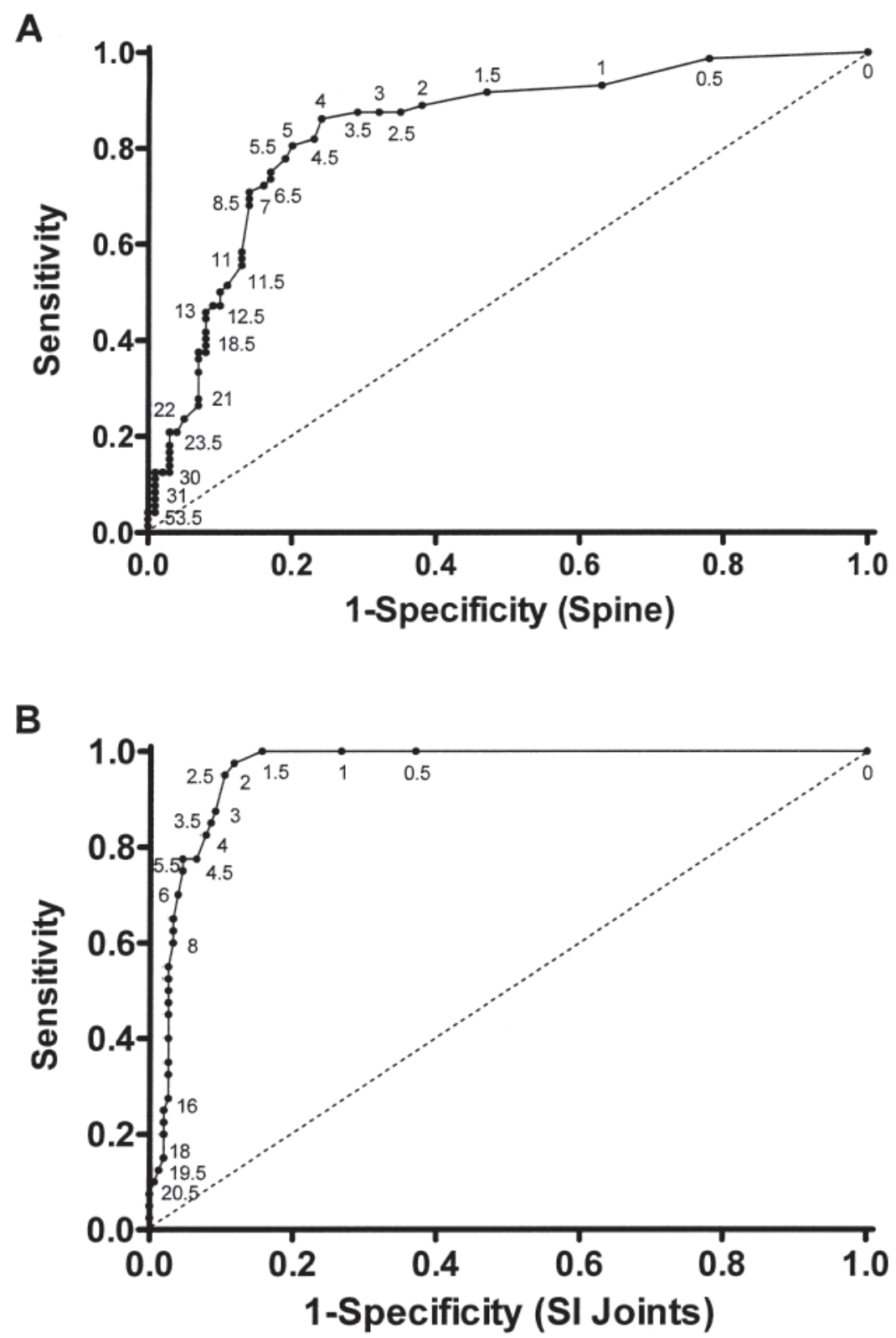

Figure 1. ROC curves for absolute change in the spine (A) and sacroiliac (SI) joint (B) SPARCC scores and global evaluation of "change" (all visit comparisons combined). ROC curves were generated using a logistic regression model of "change"/"no change." Ranges of 4.0-5.0 and 2.0-2.5 demonstrate values with sufficiently high levels of sensitivity and specificity for MRI readings of the spine and SI joints, respectively.

pain scores has been reported to be relatively poor ${ }^{11,12,25,26}$. A beneficial effect of treatment on inflammation as detected by MRI may be observed even in the absence of a clinical response $^{12}$. Nonetheless, MRI provides additional data on disease activity and response to therapeutics that cannot be provided by assessment of clinical measures alone, specifically in AS, where the most commonly used clinical response measures are largely subjective.

The scoring systems used for spine and SI joint MRI have not been widely adopted within the clinical practice setting given the time and specialized training required to perform such scoring. In addition, their applicability has not been adequately translated from the clinical trial setting to the individual patient seen in the clinical practice environment, a setting in which it is often desirable to assess a patient for changes in disease activity that are clinically relevant. MCID cutoffs for a variety of instruments examined in patients with AS (e.g., BASDAI, BASFI) have been described ${ }^{27}$. Minimal CII has also been defined for patient global assessment of disease activity and pain in patients with $\mathrm{AS}^{28}$. We have estimated 

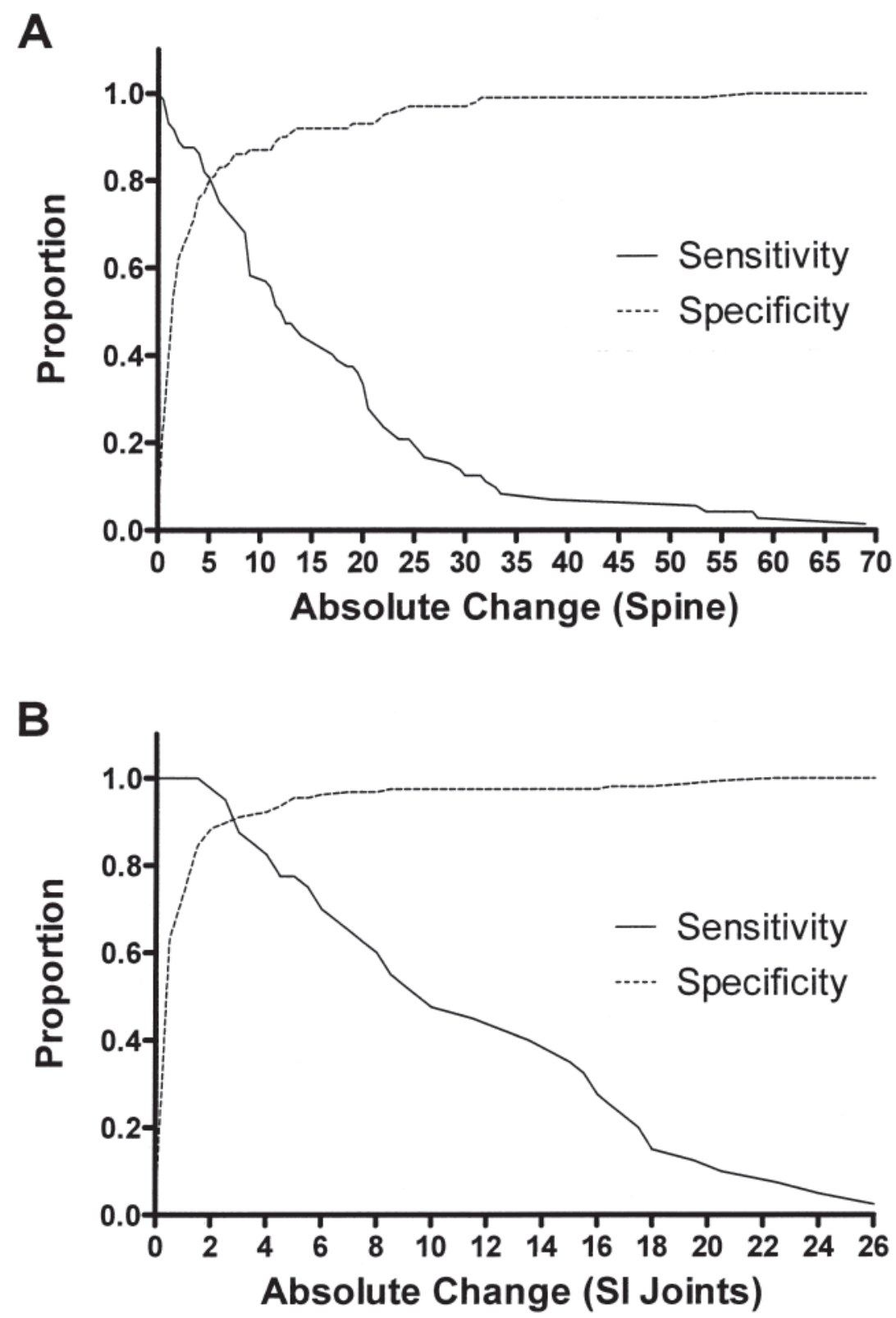

Figure 2. Identification of minimally important change in SPARCC scores of the spine and sacroiliac (SI) joints. The sensitivity and specificity of the SPARCC indices were plotted as a function of absolute change in score for the spine (A) and SI joints (B). The intersection of the sensitivity and specificity curves indicates the threshold at which "change" can be separated from "no change."

using a data-driven approach, with the overall assessment of change seen on MRI by expert radiologist readers as an external anchor, that the MIC for the SPARCC MRI assessments of the spine and SI joint are 5.0 and 2.5 units, respectively. This cutoff can be useful in discriminating treatment groups and particularly in discriminating clinical responders from nonresponders in patients receiving conventional therapy. Patients taking a placebo in our study continued to receive conventional background therapy during the trial. All Week 12 clinical response measures (ASAS20, ASAS40, BASDAI50,
ASDAS-CII, ASDAS-MI) were significantly higher in placebo-treated patients with SPARCC SI joint MRI improvement $>2.5$ units compared with placebo-treated patients who did not demonstrate this magnitude of change in the MRI score. Interestingly, treatment with adalimumab uncoupled clinical response from MRI improvement.

The methodology for defining the MIC for imaging instruments in rheumatology can be considered in 2 broad categories $^{29,30}$. The first is a statistical approach in which the distribution of the data is used to determine the amount of change 
Table 4. Relationship between Week 12 clinical response and improvements greater than minimally important change (MIC) in spine or SI joint SPARCC scores.

\begin{tabular}{|c|c|c|c|c|c|c|c|c|c|c|}
\hline \multirow[b]{2}{*}{ Spine: improvement $>$ MIC (5 units) } & \multicolumn{2}{|c|}{ ASAS20 } & \multicolumn{2}{|c|}{ ASAS40 } & \multicolumn{2}{|c|}{ BASDAI50 } & \multicolumn{2}{|c|}{ ASDAS CII } & \multicolumn{2}{|c|}{ ASDAS MI } \\
\hline & $\mathrm{ADA}$ & $\mathrm{PBO}$ & ADA & PBO & ADA & PBO & ADA & $\mathrm{PBO}$ & ADA & $\mathrm{PBO}$ \\
\hline No, $n=48: 32$ PBO, 16 ADA & $56.3^{*}$ & 21.9 & $50.0 * *$ & 9.4 & 31.3 & 12.5 & 56.3 & 31.3 & 56.3 & 28.1 \\
\hline SI joints: improvement $>$ MIC (2.5 units) & ADA & $\mathrm{PBO}$ & ADA & PBO & ADA & PBO & ADA & $\mathrm{PBO}$ & ADA & $\mathrm{PBO}$ \\
\hline No, $\mathrm{n}=57: 30 \mathrm{PBO}, 27 \mathrm{ADA}$ & $44.4^{*}$ & 16.7 & $40.7 * * *$ & 0 & $33.3 * *$ & 3.3 & $59.3^{*}$ & 26.7 & $55.6^{*}$ & 23.3 \\
\hline Yes, $\mathrm{n}=25: 14 \mathrm{PBO}, 11 \mathrm{ADA}$ & 54.6 & $50.0^{\dagger}$ & 54.6 & $28.6^{\dagger \dagger}$ & 45.5 & $35.7^{\dagger \dagger}$ & 81.8 & $64.3^{\dagger}$ & 72.7 & $57.1^{\dagger}$ \\
\hline
\end{tabular}

Differences between treatment groups at the $* \mathrm{p}<0.05$, $* *<0.01$, and $* * *<0.001$ level, based on chi-square; differences within treatment groups at the $\dagger \mathrm{p}<0.05,{ }^{\dagger \dagger}<0.01$, based on chi-square. SI: sacroiliac; SPARCC: SpondyloArthritis Research Consortium of Canada; ASAS: Association of SpondyloArthritis International Society; BASDAI: Bath Ankylosing Spondylitis Disease Activity Index; ASDAS: Ankylosing Spondylitis Disease Activity Score; CII: clinically important improvement; MI: major improvement; ADA: adalimumab; PBO: placebo.

that can be reliably discriminated from the interreader measurement error of the scoring method. Because this approach is based only on statistical analyses, it is not known to what degree it represents a clinically relevant change. A second approach uses anchor-based methods: an external criterion, such as patient global assessment, is used to estimate a relevant or important change. A limitation of this approach is that it does not take measurement precision into account; thus, information is lacking on whether an important change lies within the measurement error of the instrument. We selected an anchor-based approach to estimate the MIC.

The choice of an external anchor for estimation of a clinically relevant MIC can pose challenges for an imaging instrument, particularly in AS where a poor correlation has been demonstrated with clinical outcomes. While increasing evidence shows that inflammation observed on MRI has predictive validity for structural damage ${ }^{5,31}$, it is unclear how this might affect treatment decisions in the absence of therapies that can inhibit radiographic progression in AS. Therefore, we chose an external anchor that is based on an expert radiologist's opinion of what constitutes "change" based on overall interpretation of the MRI scans. Consequently, it is important to emphasize that this MIC defined in this manner reflects an important change in an MRI lesion, which does not necessarily imply a concomitant MCID in the clinical status of the patient.

The spine SPARCC score assesses inflammation in a dichotomous manner (present/absent) in quadrants of the 6 most severely affected DVU. The identified MIC (change of at least 5.0 SPARCC units) indicates a change of 5 quadrants with BME. It is unlikely that scoring all 23 DVU would affect the cutoff for the MIC because the DVU that are not scored have less severe inflammation and would therefore not likely influence the GEC. Similarly, the SPARCC SI joint score assesses inflammation in a dichotomous manner in SI joint quadrants, with an MIC of 2.5 indicating a change in at least 2-3 quadrants with BME.

The MIC thresholds identified in this analysis allowed discrimination of clinical responders from nonresponders in patients who received conventional therapy, but only for assessments of the SI joints. In contrast, improvements in SPARCC MRI scores were uncoupled from clinical responses in patients treated with adalimumab, where improvement in MRI was evident in virtually all patients as seen on cumulative probability data ${ }^{12}$. These data are reminiscent of responses observed following TNF- $\alpha$ inhibition in patients with rheumatoid arthritis (RA). Patients with RA who receive a TNF- $\alpha$ inhibitor show low levels of radiographic progression across the entire range of clinical responses ${ }^{32,33,34,35,36}$.

Limitations of the analyses presented here include the possibility that these cutoffs might differ in patients with a shorter disease duration prior to the appearance of tissue metaplasia with fat and new bone. The appearance of structural lesions may lead to increased difficulty in the assessment of inflammatory lesions. This may be particularly challenging in the SI joints, where inflammation is often seen bordering areas of fat infiltration in well established disease. Readers may differ in their approach to recording inflammation, and published SI joint scoring methods do not specify the approach to quantifying inflammation in the presence of such structural abnormalities ${ }^{8,9,19}$. While the SPARCC methods score inflammation in a dichotomous manner even in the presence of structural lesions, this inflammation is often of low signal intensity on STIR and difficult to differentiate from normal marrow signal. This might also account for the interreader reliability of the GEC being about $70 \%-80 \%$.

We used a data-driven approach and an external anchor relevant to routine practice to estimate the MIC for spinal and SI joint inflammation as measured by the SPARCC MRI indices in patients with AS. This can facilitate the identification of responders to therapeutic intervention and predictors of response based on MRI. It may also contribute to the further assessment of MRI as a prognostic indicator for structural damage in patients with AS.

\section{ACKNOWLEDGMENT}

The authors thank members of the M03-606 study group [Mary Jane Bell (Toronto), Denis Choquette (Montreal), Robert Inman (Toronto), Edward C. 
Keystone (Toronto), William O. Martin (Calgary), Wojciech P. Olszynski (Saskatoon), Proton Rahman (St. John's), and Kamran Shojania (Vancouver)], as well as Benjamin Wolfe, $\mathrm{PhD}$, of Abbott, for editorial assistance with the drafting and revision of this report.

\section{REFERENCES}

1. Anderson JJ, Baron G, van der Heijde D, Felson DT, Dougados M. Ankylosing Spondylitis Assessment Group preliminary definition of short-term improvement in ankylosing spondylitis. Arthritis Rheum 2001;44:1876-86.

2. van der Heijde D, Dougados M, Davis J, Weisman MH, Maksymowych W, Braun J, et al. ASsessment in Ankylosing Spondylitis International Working Group/Spondylitis Association of America recommendations for conducting clinical trials in ankylosing spondylitis. Arthritis Rheum 2005;52:386-94.

3. Creemers MC, Franssen MJ, van't Hof MA, Gribnau FW, van de Putte LB, van Riel PL. Assessment of outcome in ankylosing spondylitis: An extended radiographic scoring system. Ann Rheum Dis 2005;64:127-9.

4. Maksymowych WP. Imaging in spondyloarthritis. Adv Exp Med Biol 2009;649:17-36.

5. Oostveen J, Prevo R, den Boer J, van de Laar M. Early detection of sacroiliitis on magnetic resonance imaging and subsequent development of sacroiliitis on plain radiography. A prospective, longitudinal study. J Rheumatol 1999;26:1953-8.

6. Bennett AN, McGonagle D, O'Connor P, Hensor EM, Sivera F, Coates LC, et al. Severity of baseline magnetic resonance imaging-evident sacroiliitis and HLA-B27 status in early inflammatory back pain predict radiographically evident ankylosing spondylitis at eight years. Arthritis Rheum 2008;58:3413-8.

7. Maksymowych WP, Chiowchanwisawakit P, Clare T, Pedersen SJ, Ostergaard M, Lambert RG. Inflammatory lesions of the spine on magnetic resonance imaging predict the development of new syndesmophytes in ankylosing spondylitis: Evidence of a relationship between inflammation and new bone formation. Arthritis Rheum 2009;60:93-102.

8. Maksymowych WP, Inman RD, Salonen D, Dhillon SS, Krishnananthan R, Stone M, et al. Spondyloarthritis Research Consortium of Canada magnetic resonance imaging index for assessment of spinal inflammation in ankylosing spondylitis. Arthritis Rheum 2005;53:502-9.

9. Maksymowych WP, Inman RD, Salonen D, Dhillon SS, Williams M, Stone M, et al. Spondyloarthritis Research Consortium of Canada magnetic resonance imaging index for assessment of sacroiliac joint inflammation in ankylosing spondylitis. Arthritis Rheum 2005;53:703-9.

10. Landewe RB, Hermann KG, van der Heijde DM, Baraliakos X, Jurik AG, Lambert RG, et al. Scoring sacroiliac joints by magnetic resonance imaging. A multiple-reader reliability experiment. J Rheumatol 2005;32:2050-5.

11. Maksymowych WP, Salonen D, Inman RD, Rahman P, Lambert RG. Low-dose infliximab (3 mg/kg) significantly reduces spinal inflammation on magnetic resonance imaging in patients with ankylosing spondylitis: A randomized placebo-controlled study. J Rheumatol 2010;37:1728-34.

12. Lambert RG, Salonen D, Rahman P, Inman RD, Wong RL, Einstein $\mathrm{SG}$, et al. Adalimumab significantly reduces both spinal and sacroiliac joint inflammation in patients with ankylosing spondylitis: A multicenter, randomized, double-blind, placebo-controlled study. Arthritis Rheum 2007;56:4005-14.

13. Beaton DE, Bombardier C, Katz JN, Wright JG, Wells G, Boers M, et al. Looking for important change/differences in studies of responsiveness. OMERACT MCID Working Group. Outcome Measures in Rheumatology. Minimal clinically important difference. J Rheumatol 2001;28:400-5.
14. Bruynesteyn K, van der Heijde D, Boers M, Saudan A, Peloso P, Paulus H, et al. Determination of the minimal clinically important difference in rheumatoid arthritis joint damage of the Sharp/van der Heijde and Larsen/Scott scoring methods by clinical experts and comparison with the smallest detectable difference. Arthritis Rheum 2002;46:913-20.

15. van der Linden S, Valkenburg HA, Cats A. Evaluation of diagnostic criteria for ankylosing spondylitis. A proposal for modification of the New York criteria. Arthritis Rheum 1984;27:361-8.

16. Bland JM, Altman DG. Statistical methods for assessing agreement between two methods of clinical measurement. Lancet 1986;1:307-10.

17. Bland JM, Altman DG. Comparing two methods of clinical measurement: A personal history. Int J Epidemiol 1995;24 Suppl 1:S7-14.

18. Machado P, Landewe R, Lie E, Kvien TK, Braun J, Baker D, et al. Ankylosing Spondylitis Disease Activity Score (ASDAS): Defining cut-off values for disease activity states and improvement scores. Ann Rheum Dis 2011;70:47-53.

19. Braun J, Baraliakos X, Golder W, Brandt J, Rudwaleit M, Listing $\mathrm{J}$, et al. Magnetic resonance imaging examinations of the spine in patients with ankylosing spondylitis, before and after successful therapy with infliximab: Evaluation of a new scoring system. Arthritis Rheum 2003;48:1126-36.

20. Baraliakos X, Brandt J, Listing J, Haibel H, Sorensen H, Rudwaleit $\mathrm{M}$, et al. Outcome of patients with active ankylosing spondylitis after two years of therapy with etanercept: Clinical and magnetic resonance imaging data. Arthritis Rheum 2005;53:856-63.

21. Baraliakos X, Davis J, Tsuji W, Braun J. Magnetic resonance imaging examinations of the spine in patients with ankylosing spondylitis before and after therapy with the tumor necrosis factor alpha receptor fusion protein etanercept. Arthritis Rheum 2005;52:1216-23.

22. Rudwaleit M, Baraliakos X, Listing J, Brandt J, Sieper J, Braun $J$. Magnetic resonance imaging of the spine and the sacroiliac joints in ankylosing spondylitis and undifferentiated spondyloarthritis during treatment with etanercept. Ann Rheum Dis 2005;64:1305-10.

23. Braun J, Landewe R, Hermann KG, Han J, Yan S, Williamson P, et al. Major reduction in spinal inflammation in patients with ankylosing spondylitis after treatment with infliximab: Results of a multicenter, randomized, double-blind, placebo-controlled magnetic resonance imaging study. Arthritis Rheum 2006;54:1646-52.

24. Bollow M, Fischer T, Reisshauer H, Backhaus M, Sieper J, Hamm B, et al. Quantitative analyses of sacroiliac biopsies in spondyloarthropathies: $\mathrm{T}$ cells and macrophages predominate in early and active sacroiliitis - cellularity correlates with the degree of enhancement detected by magnetic resonance imaging. Ann Rheum Dis 2000;59:135-40.

25. Bredella MA, Steinbach LS, Morgan S, Ward M, Davis JC. MRI of the sacroiliac joints in patients with moderate to severe ankylosing spondylitis. AJR Am J Roentgenol 2006;187:1420-6.

26. Goh L, Suresh P, Gafoor A, Hughes P, Hickling P. Disease activity in longstanding ankylosing spondylitis: A correlation of clinical and magnetic resonance imaging findings. Clin Rheumatol 2008;27:449-55.

27. Pavy S, Brophy S, Calin A. Establishment of the minimum clinically important difference for the Bath Ankylosing Spondylitis Indices: A prospective study. J Rheumatol 2005;32:80-5.

28. Kvamme MK, Kristiansen IS, Lie E, Kvien TK. Identification of cutpoints for acceptable health status and important improvement in patient-reported outcomes, in rheumatoid arthritis, psoriatic arthritis, and ankylosing spondylitis. J Rheumatol 2010;37:26-31 .

29. Crosby RD, Kolotkin RL, Williams GR. Defining clinically meaningful change in health-related quality of life. J Clin 
Epidemiol 2003;56:395-407.

30. de Vet HC, Ostelo RW, Terwee CB, van der Roer N, Knol DL, Beckerman H, et al. Minimally important change determined by a visual method integrating an anchor-based and a distribution-based approach. Qual Life Res 2007;16:131-42.

31. Blum U, Buitrago-Tellez C, Mundinger A, Krause T, Laubenberger J, Vaith P, et al. Magnetic resonance imaging (MRI) for detection of active sacroiliitis - A prospective study comparing conventional radiography, scintigraphy, and contrast enhanced MRI. J Rheumatol 1996;23:2107-15

32. Smolen JS, Han C, Bala M, Maini RN, Kalden JR, van der Heijde $\mathrm{D}$, et al. Evidence of radiographic benefit of treatment with infliximab plus methotrexate in rheumatoid arthritis patients who had no clinical improvement: A detailed subanalysis of data from the anti-tumor necrosis factor trial in rheumatoid arthritis with concomitant therapy study. Arthritis Rheum 2005;52:1020-30.

33. Landewe R, van der Heijde D, Klareskog L, van Vollenhoven R, Fatenejad S. Disconnect between inflammation and joint destruction after treatment with etanercept plus methotrexate: Results from the trial of etanercept and methotrexate with radiographic and patient outcomes. Arthritis Rheum 2006;54:3119-25.
34. Smolen JS, van der Heijde DM, St. Clair EW, Emery P, Bathon JM, Keystone EC, et al. Predictors of joint damage in patients with early rheumatoid arthritis treated with high-dose methotrexate with or without concomitant infliximab: Results from the ASPIRE trial. Arthritis Rheum 2006;54:702-10.

35. Emery P, Genovese MC, van Vollenhoven R, Sharp JT, Patra K, Sasso EH. Less radiographic progression with adalimumab plus methotrexate versus methotrexate monotherapy across the spectrum of clinical response in early rheumatoid arthritis. J Rheumatol 2009;36:1429-41.

36. Smolen JS, Han C, van der Heijde DM, Emery P, Bathon JM, Keystone EC, et al. Radiographic changes in rheumatoid arthritis patients attaining different disease activity states with methotrexate monotherapy and infliximab plus methotrexate: The impacts of remission and tumour necrosis factor blockade. Ann Rheum Dis 2009;68:823-7. 